\title{
Trust Your Instincts: The Relationship Between Intuitive Decision Making And Happiness
}

\author{
Simone S. Stevenson \\ BPsychSc (Hons) Bond University, Gold Coast, Australia \\ Richard E. Hicks \\ PhD Psychology Bond University, Gold Coast, Australia.
}

doi: 10.19044/esj.2016.v12n11p463 URL:http://dx.doi.org/10.19044/esj.2016.v12n11p463

\begin{abstract}
Epstein (1994; 2003) proposed that there are two cognitive information processing systems that operate in parallel: the intuitive thinking style and the rational thinking style. Decisional fit occurs when the preferred thinking style is applied to making a decision and research has shown that this fit increases the value of the outcome of a decision. Additionally, decisional fit leads to less regret, even when post hoc evaluations show the decision to be incorrect. It has not yet been determined whether decisional fit correlates with greater happiness and hence, the purpose of the current study was to investigate the difference between styles of thinking, styles of decision making and the impact of decisional fit on happiness scores. Individual differences in thinking and decision style were measured using an online interactive questionnaire $(N=100)$, and an ANOVA, hierarchical multiple regression, and a series of $t$-tests, were used to investigate the relationship between thinking style, decision style, decisional fit, and happiness, thereby addressing a gap in the existing literature. The major findings from the current study show that intuitive thinking has a strong positive correlation with happiness; that intuitive thinkers are more likely to utilize intuitive decisional style, than rational thinkers; and that when both rational and intuitive thinkers experienced decisional fit, higher ratings of happiness were reported. Explanations and recommendations for future studies are outlined in the discussion.
\end{abstract}

Keywords: Intuitive thinking; rational thinking; decisional fit; decisional style; happiness; satisfaction with choice

\section{Introduction}

Happiness has been described as an optimal state of being; not merely a fleeting emotional state, but more a deep and abiding sense of 
flourishing (Ricard, 2007). Happiness does not occur automatically with acquisition or fortuitous circumstance, but through personal construction requiring patience, effort, and time (Peterson, Park, \& Seligman, 2005; Ryan \& Deci, 2001; Seligman, Steen, Park, \& Peterson, 2005). As the most common answer to what people want from life is to be happy, happiness is still a relatively unexplored domain of research (Lyubomirsky, Tkach, \& Dimatteo, 2006; Helliwell, Layard, \& Sachs, 2012). It may be that how individuals think, process information, and make decisions contributes to overall subjective happiness. Specifically, if there is an alignment between an individual's dominant thinking style, either rational or intuitive, and this same thinking style is applied to making a choice, the congruence between thought and action may elevate subjective happiness ratings via the concept of regulatory fit (Betsch \& Kunz, 2008; Higgins, 2005; Witterman, van den Berken, Claes, \& Godoy, 2009). This aim of this paper is to explore the idea that differences in happiness ratings may occur in individuals as a consequence of decisional fit; a concept similar to person environment fit (Holland, 1997), but applied to thinking styles and decision making (Higgins, 2005). Betsch and Kunz (2008) found that when participants experienced decisional fit a higher perceived value was placed on the decision, and less regret was felt even if the decision was incorrect in hindsight (De Vries, Holland, \& Witterman, 2008). What has not as yet been addressed in the previous literature is whether there is a correlation between decisional fit and happiness, as opposed to feelings of lower remorse associated with decisions made (De Vries et al., 2008; Diener, Fujita, Tay, \& Biswas-Diener, 2012; Higgins, 2005).

\section{Happiness}

Currently, there is no universally agreed upon definition for the subjective state of happiness and words like life satisfaction, contentment and wellbeing are often used interchangeably to describe the state of being happy (Ryan \& Deci, 2001). For the purposes of the current study the definition of happiness shall be derived from the three-fold concept of global happiness proposed by Seligman and Csikszentmihalyi (2000) and defined as a combination of pleasure, flow, engagement and meaningful purpose (Lyubomirsky, Tkach, \& Dimatteo, 2006; Seligman et al., 2005). This global pathway to happiness minimises the heritability of personality attributes, and it has good cross cultural generalizability (Lyubomirsky, Tkach, \& Dimatteo, 2006). In order to make the decision that one is happy, it must be evaluated cognitively (Kahneman, 1999). This means that in order to self-determine the answer, yes I am happy or no I am not happy a decision with regard to happiness must be made. There is however, a paucity of research as to whether happiness is determined rationally, where a list of 
particular attributes, circumstances and qualities are considered, or determined intuitively, as a deep gut level reaction that is an integrated pool of personal retrospectives and emotional attributions of experience. It is entirely possible that the rational and intuitive systems have bidirectional interplay and that the combination of both systems answers the question of perceived happiness (Helliwell, Layard, \& Sachs, 2012).

\section{Thinking styles}

Cognitive Experiential Self Theory (CEST) is a model designed to measure two distinct cognitive information processing styles, a rational system and an intuitive system within the context of a global theory of personality (Epstein, 1994). CEST is a paradigm that incorporates the conceptual principles of learning theory, cognitive theory and self-theory (Pacini \& Epstein, 1999). Epstein (1994, 2003) proposed that these two systems have different approaches to evaluating judgements, choices and for making decisions (Epstein \& Meier, 1989; Kahneman, 2011). The rational system is the domain of new learning where information is encoded in numbers, words, symbols and concepts that allow for conscious reasoning and logical justification (Norris \& Epstein, 2011). It is a conscious thought process which requires attention and effort to deliberate and problem solve information. Interacting, and operating in parallel, is a second system that is a fast, instinctual, emotionally driven cognitive aspect of self, known as the intuitive system (Kahneman, 2011; Norris \& Epstein, 2011). The intuitive system is the domain of tacit and implicit knowledge, cognitive schemas, and emotional memory. It operates through heuristics, individual knowledge, memory, and interpretation of past and present events. This system conceptualizes possibility via imagination through which it provides expectations of the future (Sayegh, Anthony, \& Perrewe, 2004).

Research has shown that individuals have a slight preference for one of these cognitive domains, either rational or intuitive, thereby favouring one thinking style over the other (Betsch, 2004; Kahneman, 2011). Even though individual's have a preferred thinking style, when it comes to making decisions that preference or decisional style is not always applied to making a choice. In societies where learning is based upon memorization of facts and tests of competence are designed and measured on evidence based responding, children grow up classically conditioned to be able to justify a logical explanation for behaviour and thought (Norris \& Epstein, 2011; Sladek, Bond, \& Phillips, 2010). For example, when asked why a particular choice was made, answers that show sequential reasoned thought are respected in spite of individual differences between answers. However, responses that are more intuitive such as it just felt right to me or I do not know why I made that decision but it happened in hindsight to turn out ok, 
are labelled flaky and inadequate as a justification for thought or behaviour as they do not follow the display rules of formal logic (De Vries, Holland, \& Witterman, 2008; Sayegh, Anthony, \& Perrewe, 2004; Sinclair \& Ashkanasy, 2005). Society endorses choices made upon sound justifiable logic which is the domain of the rational mind, and in many situations there is a stigma associated with decisions made upon gut feeling or instinct, the domain of the intuitive mind (Sinclair \& Ashkanasy, 2005). Some researchers go as far as to claim that emotionality should be forfeited or suppressed in order to make accurate respectable decisions (Damasio, 1994). It has however, been found that individuals who have a preference for intuitive thinking are more effective when dealing with tasks that are nondecomposable, require insight and holistic judgements that are not hindered by the execution of sequentially ordered analytic reasoning (Dane, Rockman, \& Pratt, 2012). In a study on management strategy on the 9/11 terrorist attacks of the World Trade Centre fast sound decisions had to be made in situations of high uncertainty, fear and with an absence of all facts (Bram, Orr, \& Rapaport, 2002; Sayegh, Anthony, \& Perrewe, 2004). Many heuristic intuitive decisions were made within the context situational constraints involving large numbers of people and organisational systems. The accuracy of these decisions in post hoc evaluation was found higher where there was experience and domain expertise, and although the preference for intuitive thinking itself does not change over the lifespan, tacit and implicit knowledge does (Dane, Rockman, \& Pratt, 2012; Pacini \& Epstein, 1999). Likewise, research into leaders, senior managers and CEO's show that where there is high domain expertise and under time pressured crisis conditions, intuitive decision making is often used effectively where good judgements are largely dependent upon emotional signalling (Bechara, Damasio, \& Damasio, 2000). Good judgements sometimes involve issues of morality and ethical virtue, which has been investigated with regard to thinking and decisional styles. Zhong (2008) proposes that the rules of the rational mind can override the instinctual feeling that is associated with conscience, thus supporting the idea of intuitive decision making for sound moral judgements. This idea conflicts with research from Pacini \& Epstein (1999) who found that higher conscientiousness and morality were associated with rational thinking and rational decisional processes. As morality is considered a key tenent associated with happiness as stated by various happiness philosophers (Seligman \& Csikszentmihalyi, 2000) the current study seeks to understand whether there is a relationship between a particular thinking and decisional style with happiness, which may shed some light for future research on ethical decision making.

The main body of research shows that reasoned deliberated decision making, although generally condoned by society as the superior cognitive 
style to intuitive decision making, it does not always fit with environmental contexts and situations of uncertainty. Individuals who show a preference for the rational thinking style are better suited to tasks requiring the evaluation of facts derived from time intensive analysis, evidence and proof (Epstein, 2003; Kahneman, 2011). However, rational decision making has also been linked with procrastination, higher stress, anxiety and depression, where for some individuals the search for the most factual and logically correct answer can induce negative affective states (Buss, 2000; Leykin \& DeRubeis, 2010). Conversely, intuitive thinking is positively correlated with high relationship satisfaction, popularity, creativity, imagination and empathy (Norris \& Epstein, 2011), but on the darker side intuitive thinking is also related to impulsivity, superstitious beliefs and psychopathy (Freeman, Evans, \& Lister, 2012). As some of the highest correlates to happiness are strong interpersonal relationships, popularity, (Diener \& Seligman, 2002) as well as having the quality of faith (Stark \& Maier, 2008) it is posited that the current study would find a relationship between intuitive thinking and happiness.

\section{Decisional styles}

Even though each individual shows a preference for a particular thinking style, the preferred thinking style is not always applied to making a decision. In fact, situations arise daily where the preferred thinking style is ignored in favour of actions and decisions made from the opposite cognitive domain (Kahneman, 2011; Zhong, 2008). For example, an individual with a preference for rational thinking might conclude that spending money on a luxury item is unwise based upon the financial facts presented in a bank statement. However, the intuitive mind might override these facts and the desired item may still be purchased, indicating an intuitive/emotional decisional style from a rational thinker. For those individuals who have a preference for intuitive thinking, and who are culturally and societally conditioned to apply rational logic to making a decision, less resultant satisfaction with the decision may occur as a result of cognitive conflict (Betsch \& Kunz, 2008; Higgins, 2005; Witterman, van den Berken, Claes, \& Godoy, 2009). That is, the decisional style or the action process demonstrated to make a decision is not congruent with the preferred thinking style. A decision can be made rationally or intuitively, and information will oscillate between the two systems until a choice is made (Betsch \& Kunz, 2008; Dane, Rockman, \& Pratt, 2012). The cognitive domain where the action, behaviour and commitment to a choice is made, either the intuitive mind or the rational mind, is known as the decisional style (Pacini \& Epstein, 1999). This is the system that accepts a solution and commits to an actionable decision when faced with a choice, in that particular situation (Betsch \& Kunz, 2008). 


\section{Decisional fit}

Research into fit theory suggests that when there is personenvironment fit, or a client-therapist fit, it is a robust predictor of well-being and personal satisfaction (Frank, 1971; Holland, 1997; Rogers, 2012; Walsh, Craik, \& Price, 2000). The concept of decisional fit extends upon this theoretical underpinning showing that when one of two preferred thinking strategies, either a predominant rational thinking style or a preferred intuitive thinking style that is then applied to making a decision (decisional style), the individual would experience decisional fit (Betsch \& Kunz, 2008; Higgins, 2005; Walsh, Craik, \& Price, 2000). That is, rational thinkers who make a decision rationally based upon facts, logic and reason, and intuitive thinkers who make a decision intuitively (based upon instinct, emotion or feeling) would experience decisional fit if the preferred thinking style is acted upon congruently when faced with a choice (Betsch \& Kunz, 2008). By applying the concept of fit theory to decision making (decisional fit) it may increase subjective happiness ratings simply through alignment with congruent cognitive style. Regulatory fit increases the positive value and feeling of rightness of subjective evaluations (Betsch \& Kunz, 2008; Higgins, 2005; Rogers, 2012).

What has not as yet been addressed in the previous literature is whether decisional fit actually increases subjective happiness ratings, as opposed to simply reducing disappointment, as well as providing a psychological damage control mechanism with regard to ill-fitting choices (Betsch \& Kunz, 2008; Lyubomirsky, Tkach, \& Dimatteo, 2006). Preferred decision making strategies become a routine or habitual way of responding over time. That is, a preferred style of decision making (either intuitive or rational) becomes a stable preference within the individual (Messick, 1976). If an individual naturally seeks decisional fit an elevation of positive value will be associated with the learned strategy (Betsch, 2004, 2008). However, decisional misfit can also become a learned strategy of responding to decision making and it may be associated with less perceived resultant satisfaction with making choices (Broder \& Schiffer, 2006). It is proposed that the individuals who have a preferred intuitive thinking style, and who apply the intuitive decisional style to achieve decisional fit, would experience higher subjective ratings of happiness, when compared with individuals who have a preferred rational thinking style or those who experience decisional misfit. Decisional misfit occurs when the preferred thinking or decisional style is not used when making a decision (Betsch \& Kunz, 2008; Higgins, 2005). That is, for example, when an intuitive thinker makes a decision rationally, or when a rational thinker makes a decision intuitively; this would be decisional misfit. The implications of finding a link between preference for intuitive thinking and happiness, via decisional fit 
has practical utility with regard to understanding whether happiness is recognized, assessed, harnessed and processed differently between intuitive and rational thinkers (Epstein \& Pacini, 2001; Ramirez, Millana, ToldosRomero, Bonniot-Cabanac, \& Cabanac, 2009). If links are found between a particular thinking style, decisional style and decisional fit with regard to happiness ratings, this would provide insight into the value of being true to self (Raffaldi, Iannello, Vittani, \& Antonietti, 2012). This could also provide some insight as to what kind of therapy would be suited to each of the different thinking styles. If rational thinkers who experience decisional fit, and if higher happiness is ascribed based upon logic and reason, then clearly articulated facts about reasons to change would be appropriate, as personal happiness levels would increase. If however, the same rational logic and reason for change was applied to an intuitive thinker, decisional misfit may occur thus reducing the potential chances for change. Hypothetically, if an intuitive thinker was presented with emotive or feeling based reasons for change, and decisional fit occurred, then the correlated subjective happiness would provide motivation based upon congruence of thought and feeling to inspire change in these circumstances, for this type of individual (Epstein \& Pacini, 2001; Witterman et al., 2009). One of the intentions of this research is to uncover one possible reason for why some conventional therapeutic techniques are unsuccessful for some individuals, in spite of education and rehabilitation (Beck, 2011). The implications for finding a difference between the two groups may provide a deeper understanding towards motivation for personal decision strategies and personal choice behaviour, if happiness is a key driver associated with reward (Betsch \& Kunz, 2008; Buss, 2000; Epstein , Pacini, Denes-Raj, \& Heier, 1996; Leykin \& DeRubeis, 2010; Watson \& Tharp, 2013).

Based on this research, four hypotheses were formulated to investigate the relationship between the variables of preferred thinking styles, decisional style and decisional fit on the outcome variable of happiness. Specifically, they are as follows:

H1: It was hypothesized that participants who scored higher on the preference for intuition scale (intuitive thinkers) would report higher ratings of happiness than participants who scored higher on the preference for deliberation thinking scale (rational thinkers).

H2: It was hypothesized that intuitive thinkers would be more likely to make intuitive style decisions (cognitive congruence) and therefore score higher on the intuitive decisional style scale than rational thinkers.

H3: It was hypothesized that participants who scored higher on the intuitive decisional style scale would report higher scores of happiness than those participants who scored higher on the rational decisional scale. 
H4: It was also hypothesized that all participants who experienced decisional fit (either intuitive or rational decisional fit) would report higher happiness than the participants who experienced decisional misfit.

\section{Method}

\section{Participants}

Participants were psychology students from Bond University $(n=20)$ who participated in exchange for course credit. Additionally, an email invitation with a link to the online Google forms survey was sent to extended contacts known to the researcher, which continued to be forwarded by the recipients known as a chain sampling method $(n=80)$. The final sample was $N=100$, females (80\%), males (20\%) ranging in age 18 and 74 years $(M=$ $48.53, S D=16.82$ ). Of these participants $40 \%$ were partnered, and $60 \%$ were not partnered, or single. Highest level of education was categorized into tertiary and above 56\% and high school/TAFE/trade (including any education but not at tertiary level) $44 \%$. The predominant ethnicity was Australian, 67\% followed by European 18\%, American/Canadian $10 \%$ and Asian 5\%.

There was no anticipated problem with this recruitment method as research from Tat et al. (2010) found that there were no differences between thinking styles or decision making styles based upon age, race, gender, or years of occupational experience. To control for possible confounds with decisional style and self-reported happiness, criterion exclusion was implemented prior to the demographic questions (Pacini \& Epstein, 1999). Variables that may impact both decisional style and self-reported happiness ratings would be the consumption of mind altering drugs and alcohol within the previous eight hours, as well as anti-psychotic medications (Leykin \& DeRubeis, 2010). For this reason participants who had consumed alcohol or recreational drugs within eight hours, or participants who required antipsychotic medications were asked to refrain from participation in order to preserve the integrity of the data. This exclusion criterion was designed to increase the internal validity of the study but it would also limit the generalizability of the results.

\section{Procedure and materials \\ Thinking style assessment}

Participants were asked to complete the self-report 18-item Preference for Intuition and Deliberation scale (PID; Betsch, 2004) designed to measure the individual preference for intuitive thinking (PID-I) and the preference for deliberation (PID-D). The preference for deliberation scale is synonymous with the term rational thinking style. The PID inventory has robust psychometric properties with the internal reliability for PID-I ranging 
between Cronbach's alpha .76 - .81, and for the PID-D ranging between .76 .79. Discriminant validity was less than $r=-.20$ indicating a sound negative correlation between the measures. The PID scale was used as it measures the preferred thinking system (intuitive or deliberate) without capturing personality attributes or intellectual ability (Betsch, 2004). The six month test-re-test reliability was PID-I alpha $=.76$, PID-D alpha $=.74$ indicating good stability over time.

There were nine items from each of the PID-I and PID-D scales. All questions were answered on a 5-point scale from (1) strongly disagree to (5) strongly agree. An example question from the PID-I domain was "my feelings play an important role in my decisions" and from the PID-D domain "before making decisions, I first think them through." The items from each subscale were summed (range $=9-45$ ) and higher scores from one measure (PID-I or PID-D) when compared with the other (PID-I or PID-D) indicated the preferred individual thinking style. Research from Raffaldi et al. (2012) shows that the decision making style that follows from the use of the selfreport method of the PID scale is consistent and congruent with the actual methodology employed by participants in real life situations.

\section{Decisional style assessment}

The decisional style measure is to ascertain which cognitive process, either rational or intuitive, is actually used to make a decision irrespective of preferred thinking style. For example, an individual may show a preference for intuitive thinking naturally, as measured on the PID scale. However, when faced with a choice, a decision may not actually be made using the intuitive mind, but be made rationally. To measure decisional style, a new online interactive survey was formulated. This online questionnaire was conceived of and conceptually adapted from laboratory experiments conducted by several decisional style researchers (Betsch \& Kunz 2008; Horstmann, Hausmann, \& Ryf, 2010; Witterman, van den Berken, Claes, \& Godoy, 2009; Wang, 2000) in which both intuitive and rational decisional styles of participants were ascertained.

According to decision making theory, the recall of visual images would elicit an intuitive response when the decision is forced to be fast, has low task relevance, poses no immediate threat, and does not involve mathematical computations or language recall (Hedge, 2011; Horstmann et al., 2010; Kahneman, 2011). As there is no right or wrong answer to indicating a preference between two non-threatening stimuli, (e.g., a choice between two peaceful landscapes) it is less likely to activate deliberated rational contemplation and the impression would be assessed by the intuitive mind. 
Initially, participants were primed with the phrase "you will have five seconds to look at the following two images, before they fade. Then you will be required to answer a question.” By stating a five second time frame, alert focus and concentration would be induced by the intuitive system (Horstmann et al., 2010). This was repeated with a reminder phrase "you will have five seconds to look at the following images”. A matched pair of generic images (for example two different landscapes) was presented, for a total of five seconds before they faded. After the picture faded, participants were required to answer the intuitively primed section of the questionnaire please answer the following question based on your initial impression only. Please try not to think about your answer. Which do you prefer 'picture 1' or 'picture 2'. Respondents were required to quickly commit to a choice, by nominating a preference before continuing.

To induce and prime the rational mind participants were then asked to recall from memory the images and think about the qualities of each (inducing rational thought) and nominate a preference based upon either personal functional utility (rational; I think this would serve my needs better), or desire based preference (intuitive; I just like it more; it appeals to me; non-rational or emotive). This set of questions was primed with the statement now, based upon your choice please think carefully about which answer would best describe your thought process now. The words please think carefully are registered by the rational mind as rules, and the rational system must be engaged in order to comprehend this task (Horstmann et al., 2010).

The rational section permitted the respondent unlimited time before committing to an answer. A forced choice answer example was $I$ think this would be a better holiday destination for me indicating a deliberated rational decision style or I just like this one more, indicating an emotive, subjective, intuitive decision style. This set of forced choice questions was to garner decisional style; that is to measure whether a decision was made rationally or intuitively. The rational thought and intuitive feeling based questions were counterbalanced throughout the questionnaire to prevent automaticity with responding (Mitchell \& Jolley, 2007).

There were another nine questions (ten in total) that comprised this section. The format remained the same, but different sets of pictures were used, and the wording was changed slightly to match the picture content. Examples of the matched pair items included images of scenery, food, musical instruments, young animals, beverages and flowers.

To calculate which decisional style was used, each intuitive decisional style response was allocated 1 point, where rational decisional style was allocated zero. Each participant's scores were summed and 
respondent's scores that were higher than 5 out of 10 were allocated to the intuitive decisional style group.

\section{Determining decisional fit}

Decisional fit was defined as congruence between thinking style and decisional style (Higgins, 2005). This means that if participant's scores on the PID scale revealed a higher intuitive thinking style, and this emotive thinking style was used to make a decision then that response qualified as a decisional fit. The same logic was applied to rational thinking responses. Where participants did not use the preferred thinking style and apply it to making a choice, it was categorized as decisional misfit (De Vries et al., 2008). For each of the ten questionnaire items, participants were classified as either having decisional fit (intuitive thinking plus intuitive decision making, or rational thinking plus rational decision making) or having decisional misfit (preferred thinking style and an incongruent decision style). A total score for the ten items was calculated whereby a score of ten meant decisional fit for all ten items and a score of zero meant no decisional fit for all ten items. This variable was subsequently split into high decisional fit (scores above 6) and low decisional fit (scores below 6).

\section{Happiness}

The subjective happiness scale (SHS; Lyubomirsky \& Lepper, 1999) was used to measure individual self-reported subjective happiness. This is a robust measure for global subjective happiness, even though it only has four items, and Lyubomirsky et al. (2006) have found that individuals are able to accurately rate their own happiness. The internal consistency coefficients for the 4-item subjective happiness scale have ranged from alpha $=.79-.94$ ( $M$ $=.86$ ), and both test-retest reliability and convergent validity coefficients averaged $r=.72$. An example question was "some people are generally very happy. They enjoy life regardless of what is going on, getting the most out of everything. To what extent does this characterization describe you?" to be answered on a 7-point scale from (1) not at all to (7) a great deal. To score each of the items are summed and averaged (with question four reverse scored) to provide a final score of between one and seven. Scores above 3.5 indicated higher subjective happiness.

\section{Detection of Impression Management}

The short 13-item forced choice (true/false) Social Desirability Scale (SDS, Short Form C: Crowne \& Marlowe, 1960; Fischer \& Fick, 1993). This measure is a recommended inclusion for all self-report surveys to detect impression management (Reynolds \& Livingston, 2012). The internal 
consistency for the SDS short form $C$ shows Cronbach's alpha ranging from $.76-.88$, and the test-retest coefficient is $r=.89$ (Fischer \& Fick, 1993).

\section{Results}

As the participants were sampled from two different sources (Bond University students and the general public) a Multivariate Analysis of Variance (MANOVA) was performed on the dependant variables of the study, to ensure that the two groups were not significantly different from each other. Results showed that the two samples were fit to be merged in one dataset and were treated as a unified whole set, as the MANOVA yielded a non-significant outcome on the combined variables, $F(3,103)=0.41, p=$ .750. Two participants were removed from the data set for not adhering to the exclusion criteria requests and five participants scoring highly on the Marlow- Crowne SDS were also removed. The Statistical Package for Social Sciences (SPSS) version 22 was used to conduct all analyses and all analyses were read at an alpha level of .05, unless otherwise specified.

\section{Preference for intuitive or rational thinking styles}

In order to test preference for intuition and preference for rational thinking, scores on the PID were summed and participants were assigned to groups based on their scores on PID-I and PID-D (intuitive thinker or rational thinker). Participants who scored higher on PID-I were assigned to the preference for intuitive thinking category, and respondents who scored higher on PID-D were assigned to the preference for rational thinking category. Participants who had the exact same score on both PID-I and PID$\mathrm{D}$ or, who only had one point difference between the two categories, were excluded from this part of the analysis due to the more balanced dual nature of thinking style. The final sample size was $(n=84)$. Chi-square analysis revealed that there were more individuals who qualified as rational thinkers ( $n=63$ ) when compared to individuals who qualified as intuitive thinkers ( $n$ $=21), x^{2}(1)=21.00, p<.001$.

\section{Preference for intuitive or rational decision making style}

Based on the scores on the decisional style, participants were assigned to two groups: individuals favouring rational decision making or individuals favouring intuitive decision making. A median split was performed to create these categories. Results of the chi-square analyses showed that the number of individuals favouring rational decision making ( $n$ $=44$ ) was not significantly different from the number of individuals favouring intuitive decision making $(n=40), x^{2}(1)=0.19, p=.663$. The unequal group sizes found in the chi-square analyses above means that some caution is advised with the interpretation of results. Additionally, conducting 
a median split can present the risk of a Type II error, as participants with close scores are allocated to different groups and then compared to each other (Tabachnick \& Fidell, 2014).

An initial Pearson's correlation analysis was conducted to examine relationships between the key variables used in subsequent hypothesis testing (Table 1).

Table 1 Pearson's Correlation Summary Table, with Means and Standard Deviations for Rational and Intuitive Thinking, Social Desirability, Happiness and Decision Style

\begin{tabular}{lllllllll}
\hline Scale & 1 & 2 & 3 & 4 & 5 & 6 & $M$ & $S D$ \\
\hline 1.PID-D & - & & & & & 35.05 & 5.06 \\
2.PID-I & .16 & - & & & & 31.36 & 4.38 \\
3.SDS & -.02 & .06 & - & & & 7.26 & 2.83 \\
4.Happiness & .11 & $.38^{* *}$ & $.27 *$ & - & & 21.95 & 4.14 \\
5.Decision style & $-.23^{*}$ & $.29 *$ & .04 & -.05 & - & 14.44 & 2.30 \\
\hline \multicolumn{7}{c}{ Note. ${ }^{*} p<.05,{ }^{* *} p<.01,{ }^{* * *} p<.001$. PID-D = Rational thinking, PID-I = Intuitive } \\
& \multicolumn{7}{r}{ thinking, SDS = Social Desirability Scale. }
\end{tabular}

A number of significant correlations were found. There was a positive relationship between Happiness and PID-I showing that higher intuitive decision making was associated with higher happiness scores. Higher happiness scores were also associated with higher scores on the SDS scale, thereby justifying the inclusion of SDS at step 1 of the regression to control for its impact. Consistent with expectations, there was no significant relationship between happiness and PID-D, indicating that unlike intuitive thinkers, rational thinkers were not more likely to be happier. There was a significant positive correlation between intuitive thinking and intuitive decision style and a negative correlation between rational thinking and intuitive decision style. These correlations showed that intuitive thinkers were more likely to make intuitive decisions and rational thinkers were more likely to make a rational decision, which provides initial support for decisional fit theory (Betsch \& Kunz, 2008).

\section{Correlations to happiness}

A hierarchical regression was performed in order to assess the contribution of the predictor variables, rational thinking and intuitive thinking, on the criterion variable happiness, after controlling for social desirability.

The overall model with all predictors entered was significant, $F(4$, $79)=5.48, p<.001$ and this accounted for $22 \%$ of variance in happiness scores. Regression coefficients are shown in Table 2. 
Table 2 Hierarchical Regression Coefficients for Social Desirability, Rational and Intuitive Thinking as Predictors of Happiness

\begin{tabular}{cccccccc}
\hline & Predictors & $R$ & $\Delta R^{2}$ & $B$ & $S E B$ & $\beta$ & $C I(B)$ \\
\hline Step 1 & & .27 & .07 & & & & \\
& Constant & & & $19.11^{* * *}$ & 1.21 & & \\
& SDS & & & .33 & .16 & .27 & {$[.08, .70]$} \\
Step 2 & & $.47^{* *}$ & .15 & & & & \\
& Constant & & & 2.82 & 6.31 & & \\
& PID-D & & & .04 & .08 & .05 & {$[-.13, .20]$} \\
& PID-I & & & .34 & .10 & $.36^{* * *}$ & {$[.15, .53]$} \\
\hline
\end{tabular}

Note. ${ }^{*} p<.05, * * p<.01, * * * p<.001$. SDS $=$ Social Desirability Scale, PID-D = Rational thinking, PID-I = Intuitive thinking. CI (B) $=95 \%$ Confidence Interval

At step one, social desirability was a significant predictor of happiness, $F(1,82)=6.37, p=.014$ and this explained $7.2 \%$ of variance. Individuals who responded in a socially desirable manner scored higher on the happiness scale. At step two, the addition of the predictor variables (rational thinking and intuitive thinking) significantly contributed an additional $14.5 \%$ variance in happiness scores $\Delta F(3,79)=4.88, p=.004$. Intuitive thinking appeared as the strongest predictor of happiness. Close inspection of the beta weights revealed that as scores on the preference for intuitive thinking increased so did happiness scores $(\beta=.36, p<.001)$. The beta weights also showed that rational thinking did not contribute significant unique variance in predicting happiness. The finding from this study shows that intuitive thinking is correlated with higher happiness than rational thinking thus supporting the first hypothesis. These results contribute to the research from De Vries et al. (2008) that found that happier people were more likely to base decisions upon intuitive decisional style as these individuals were more comfortable trusting their feelings than rational decision makers.

\section{Thinking style and decisional style}

The current study sought to investigate whether participants categorised as intuitive thinkers would score higher on the intuitive decisional style scale than participants categorised as rational thinkers, thereby confirming a predominant use of an intuitive style of decision making, when compared to participants categorised as rational thinkers. An independent samples $t$-test was performed comparing intuitive thinkers $(n=$ 21) and rational thinkers $(n=63)$ on the dependent variable, intuitive decisional style. The results confirmed this hypothesis. Intuitive thinkers ( $M$ $=16.76, S D=2.68), t(82)=-2.89, p=.005$ scored significantly higher on the intuitive decisional style scale compared to rational thinkers $(M=15.16, S D$ 
$=2.03)$. Effect size as measured by Cohen's $d$ was 0.67, which indicated a medium to large effect size (Cohen, 1988).

The results of this finding show that intuitive thinking was related to more intuitively based decision making. This finding is congruent with previous research that shows that the commitment from intuitive thinkers to make an intuitively based decision is stronger and faster than those people who prefer rational thinking styles, who apply rational decisional style (Kahneman, 2011; Pacini \& Epstein, 1999).

\section{Decisional styles and happiness}

It was also of interest to determine whether individuals who made intuitive decisions would be significantly different on their subjective reports of happiness when compared to individuals who made rational decisions. To test this hypothesis, an Analysis of Variance (ANOVA) was computed using the independent variable of decisional style (rational; $n=44$, intuitive; $n=$ 40) on the dependent variable, happiness. All ANOVA assumptions were met, prior to conducting the analysis. The results showed a non-significant difference on the combined variables, $F(2,81)=2.04, p$ $=.136, \eta_{\mathrm{p}}{ }^{2}=.05$ with a small effect size. These results do not support hypothesis three, such that intuitive decisional style alone did not impact subjective ratings of happiness. Therefore, simply making an emotively influenced decision without considering the preferred thinking style does not correlate with higher happiness. This finding supports decisional fit theory that shows that only when there is congruence between preferred thinking style applied to choice, that higher evaluative satisfaction is perceived (Betsch, 2004; Higgins, 2005). This means that not all impulsive decisions are considered favourably by the individual making the decision. Thus, happiness is not a random occurrence that is automatically associated with intuitive decisional style.

\section{Decisional fit and happiness}

The current study aimed to investigate whether participants' decisional fit would influence happiness scores. An independent samples $t$ test was performed comparing a high decisional fit group $(n=24)$ and a low decisional fit group $(n=60)$ on the dependent variable happiness. The assumption of normality was met, however homogeneity of variance was not met $F=5.18, p=.025$, so an unequal variance estimate was used. The high decisional fit group $(M=23.63, S D=2.60), t(70.68)=-2.41, p=.004$ had significantly higher happiness scores compared to the low decisional fit group $(M=21.28, S D=4.45)$, thereby supporting the fourth hypothesis. Effect size as measured by Cohen's $d$ was 0.64 , which indicated a medium effect size (Cohen, 1988). 
This finding suggests that when there is decisional fit individuals report higher happiness than when there is decisional misfit which is in alignment with previous research (Betsch \& Kunz, 2008; Higgins, 2005). Regardless as to whether the preferred thinking style is rational or intuitive; making decisions that are congruent with personal preference indicates higher happiness potential.

\section{Conclusion}

The current study shows that intuitive thinking and decisional fit are related to higher happiness and possible implications from this finding are discussed. Behavioural learning comes from the feelings associated with reinforcement of behaviour, and it is posited that the development of a preferred thinking style occurs the same way, as heritability does not completely account for the predisposition to a particular thinking style, (De Vries et al., 2008; Diener et al., 2012; Pacini \& Epstein, 1999). If acting on decisional fit is also reinforced through an association with happiness, then the desire for congruence between the cognitive style and the synonomous action is also likely to increase over the lifespan (Messick, 1976). Intuitive decision makers are more likely to trust gut instinct based upon the belief that a sound decision is dependent upon emotional feedback (Sayegh et al., 2004). Research from Kahneman (2011) has shown that intuitive decision style can lead to an incorrect decision as it is a fast cognitive heuristic that sometimes overrides the explicit knowledge of the rational mind. Rational thinking style leads to higher self-regulatory behaviour, where stress reactivity is associated with avoiding the negative consequences of incorrect decisions. Thus rational decision makers take longer to make a decision in order to be accurate, and are less likely to commit to an intuitively based decision (Leykin \& DeRubeis, 2010). Given that approximately one third of the population show a preference for intuitive thinking, (one third are rational and one third are mixed) and society endorses and favours decisions that are logically sound, the rational style of decision making would induce decisional misfit for intuitive thinkers, and correlate with a reduction in subjective happiness appraisal (Betsch \& Kunz, 2008; Leykin \& DeRubeis, 2010; Sinclair \& Ashkanasy, 2005).

One of the strengths of the current study was that the decisional style measure was successfully translated from laboratory testing of participants (Betsch \& Kunz, 2008) to an online questionnaire, which provided a practical, cost effective and time efficient instrument. This self-report measure employed the principles demonstrated by previous research of primed intuitive and rational decisional style responses from participants by inserting small fade videos that elicited time contingent responding, thereby eliminating the need for participant-researcher interaction. This allowed 
participants to respond to the survey without the perceived pressure of compliance or altered performance (Hawthorne effects) that is usually associated with laboratory experimental conditions. The intention was to increase the accuracy of responding by participants and reduce researcher expectancy bias effects (Mitchell \& Jolley, 2007). However, until processes beyond the scope of the current study are developed such as establishing internal reliability, convergent and discriminant validity, all results must be interpreted with caution. Also the generalizability of this study was reduced due to a restricted sample size and the demographic exclusion criterion involving mind altering substances. As this was a pilot study and much useful data was obtained, these limitations could be addressed in future studies.

The results from the current study show that there is no effect of happiness through a particular thinking style or decisional style alone without decisional fit, and fit theory suggests a consequent increase in affective attribution (Higgins, 2005; Lyubomirsky et al., 2006; Walsh, Craik, \& Price, 2000). If the cognitive display rules for particular behaviours are followed by positive affectivity, then these behaviours are likely to be repeated (Beck, 2011; Messick, 1976). If negative behaviours are associated with pleasant feelings, then the decision to repeat the thinking style and action that led to the happiness is likely to reoccur (Cambria et al., 2012). Thus, the link between intuitive decision makers and higher happiness may also provide insight into maladaptive behaviours as well (Epstein \& Pacini, 2001). The impulsiveness associated with intuitive thinking, which correlates to higher happiness, may not always be based upon the moral rules condoned by society, however the individual will feel good, which could relate to a maladaptive association with happiness (Ramirez et al., 2009). This present study's findings make a practical contribution towards understanding a relationship where the decisions and behaviours that feel good are not always appropriate, which could have a practical utility in areas such as the maintaining of addictions, schadenfreude and criminal reoffending (Ramirez et al., 2009). Thus, for intuitive thinkers and intuitive decision makers, rational education to counter negative behaviour may not always prove effective, if happy feelings override logic (Beck, 2011). Emotion focused therapies may be a more prudent strategy for intuitive thinkers, in order to change maladaptive behaviours, and to reassociate happiness with virtuous morality based personal strengths, leading to positive meaning making, and adaptive happiness (Higgins, 2005; Greenberg, 2004; Seligman, Steen, Park, \& Peterson, 2005). 


\section{References:}

Bechara, A., Damasio, H., \& Damasio, A. (2000). Emotion, decision making and the orbitofrontal cortex. Oxford Journals, 10, 295-307. doi:10.1093/cercor/10.3.295

Beck, J. S. (2011). Cognitive therapy for challenging problems: What to do when the basics don't work. Guilford Press.

Betsch, C. (2004). Preference for intuition and deliberation (PID): An inventory for assessing affect- and cognition-based decision-making. Zeitschrift fur Differentielle und Diagnosische Psychologie, 25, 179-197. doi:10.1002/bdm.600

Betsch, C., \& Kunz, J. (2008). Individual strategy preferences and decisional fit. Journal of Behavioral Decision Making, 21, 532-555. doi:10.1002/bdm.600

Bram, J., Orr, J., \& Rapaport, C. (2002). Measuring the effects of the September 11 attack on New York City. Economic Policy Review, 5-20.

Broder, A., \& Schiffer, S. (2006). Adaptive flexibility and maladaptive routines in selecting fast and frugal decision strategies. Journal of Experimental Psychology: Learning, Memory, and Cognition, 32, 904-918. doi:10.1037/0278-7393.32.4.904

Buss, D. (2000). The evolution of happiness. American Psychologist, 55, 1523. doi:10.1037//0003-066X.55.1.15

Cambria, E., Livingstone, A., \& Hussain, A. (2012). The hourglass of emotions. In Cognitive behavioural systems (pp. 144-157). Berlin, Heidelberg: Springer.

Cohen, J. (1988). Statistical power analysis for the behavioral sciences (Vol. 2). Hillsdale, NJ: Lawrence Earlbaum Associates.

Crowne, D., \& Marlowe, D. (1960). A new scale of social desirability independent of psychopathology. Journal of Consulting Psychology, 24, 349-354. doi:10.1037/h0047358

Damasio, A. (1994). Descartes' error: Emotion, reason, and the human brain. New York: Putnam.

Dane, E., Rockman, K., \& Pratt, M. (2012). When should I trust my gut? Linking domain expertise to intuitive decision-making effectiveness. Organizational Behavior and Human Decision Processes, 119, 187-194. doi:10.1016/j.obhdp.2012.07.009

De Vries, M., Holland, R., \& Witterman, C. (2008). Fitting decisions: Mood and intuitive versus deliberative decision strategies. Cognition and Emotion, 22, 931-943. doi:10.1080/02699930701552580

Diener, E., Fujita, F., Tay, L., \& Biswas-Diener, R. (2012). Purpose, mood, and pleasure in predicitng satisfaction judgements. Social Indicators Research, 105, 333-341. doi:10.1007/s11205-011-9787-8 
Diener, E., \& Seligman, M. (2002). Very happy people. Psychological Science, 13, 81-84. doi:10.1111/1467-9280.00415

Epstein, S. (1994). Integration of the cognitive and the psychodynamic unconscious. American Psychologist, 49, 709-724. doi:10.1037/0003066X.49.8.709

Epstein, S. (2003). Cognitive-experiential self-theory of personality. In T. Milton, \& M. J. Lerner (Eds.), Comprehensive Handbook of Psychology, Volume 5: Personality and Social Psychology (pp. 159-184). Hoboken, NJ: Wiley \& Sons.

Epstein, S., \& Meier, P. (1989). Constructive thinking: A broad coping variable with specific components. Journal of Personality and Social Psychology, 57, 332-350. doi:ein, S., \& Meier, P. (1989). Constructive thinking: A broad coping variable with specific com10.1037/00223514.57.2.332

Epstein, S., Pacini, R., Denes-Raj, V., \& Heier, H. (1996). Individual differences in intuitive-experiential and analytical-rational thinking styles. Journal of Personality and Social Psychology, 71, 390-405. doi:10.1037/0022-3514.71.2.390

Fischer, D., \& Fick, C. (1993). Measuring social desirability: Short forms of the Marlowe-Crowne Social Desirability Scale . Educational and Psychological Measurement, 417-424. doi:10.1177/0013164493053002011

Frank, J. D. (1971). Therapeutic factors in psychotherapy. American Journal of Psychotherapy, 25, 350-361. doi:10.1176/foc.4.2.306

Greenberg, L. S. (2004). Emotion-focused therapy. Clinical Psychology \& Psychotherapy, 11, 3-16. doi:10.1037/14775-011

Hedge, J. (2011). Gaining insight into decisionmaking through a virtual world environment application. Prepared by RTI International. North Carolina: Institute for Homeland Security Solutions under contract HSHQDC-08-C-00100.

Helliwell, J., Layard, R., \& Sachs, J. (2012). World Happiness Report. The United Nations: The Earth Institute, Columbia University.

Higgins, E. T. (2005). Value from regulatory fit. Current Directions in Psychological Science, 14, 209-213. doi:10.1111/j.0963-7214.2005.00366.x Holland, J. L. (1997). Making vocational choices. Odessa, FL: PAR.

Horstmann, N., Hausmann, D., \& Ryf, S. (2010). Methods for inducing intuitive and deliberate processing modes (Vol. Psychology Press \& Routledge). (W. C. Glöckner A., Ed.) London.

Kahneman, D. (1999). Experienced utility and obective happiness: A moment based approach. In D. Kahneman, \& A. Tversky, Choices, Values and Frames ( Chapter 37). New York: Cambridge University Press and Russell Sge Foundation. 
Kahneman, D. (2011). Thinking, Fast and Slow. Random House of Canada. Leykin, Y., \& DeRubeis, R. (2010). Decision making style and depressive symptomology: Development of the Decision Styles Questionnaire. Judgement and Decision Making, 5, 506-515.

Lyubomirsky, S., \& Lepper, H. (1999). A measure of subjective happiness: Preliminary reliability and construct validation. Social Indicators Research, 46, 137-155. doi:10.1023/A:1006824100041

Lyubomirsky, S., Tkach, C., \& Dimatteo, M. (2006). What are the differences between happiness and self esteem. Social Indicators Research, 78, 363-404. doi:10.1007/s11205-005-0213-y

Messick, S. (1976). Personality consistencies in cognition and creativity. In S. Messick (E.), Individuality in learning (pp. 261-293). San Francisco: Jossey-Bass.

Mitchell, M., \& Jolley, J. (2007). Research Design Explained. Bellmont, CA: Wadsworth.

Norris, P., \& Epstein, S. (2011). An Experiential Thinking Style: Its facets and relations with objective and subjective criterion measures. Journal of Personality, 79, 1043-1080. doi:10.1111/j.1467-6494.2011.00718.x

Pacini, R., \& Epstein, S. (1999). The relation of rational and experiential information processing styles to personality, basic beliefs basic beliefs, and the ratio-bias phenomenon. Journal of Personality and Social Psychology, 76(6),. doi: 10.1037/0022-3514.76.6.972. Journal of Personality and Social Psychogy, 76, 972-987. doi:10.1037/0022-3514.76.6.972

Peterson, C., Park, N., \& Seligman, M. (2005). Orientations to happiness and life satisfaction: The full life and the empty life. Journal of Happiness Studies, 6, 25-41. doi: 10.1007/s10902-004-1278-z

Raffaldi, S., Iannello, P., Vittani, L., \& Antonietti, A. (2012). DecisionMaking styles in the Workplace: Relationships between self- report questionnaires and a contextualized measure of the analytical - systematic verses global-intuitive approach . Sage, 2, 1-11. doi:10.1177/2158244012448082

Ramirez, J., Millana, L., Toldos-Romero, M., Bonniot-Cabanac, M., \& Cabanac, M. (2009). The Pleasure of Being Aggressive in Male Incarcerated Criminals. The Open Criminology Journal, 2, 1-9. doi:1874-9178/09 Reynolds, C., \& Livingston, R. (2012). Mastering Modern Psychological Testing. New Jersey, USA: Pearson Education, Inc.

Ricard, M. (2007). Happiness: A guide to developing life's most important skill. New York: Little, Brown and Company. Retrieved from http://api.ning.com/files/6zD1QgIezd2fNdXjUEEWDL9TJyYvqR8AMp*Gk ClmH9kbAMb8I1y9aXEsDc-ZeYEOH-

Un7q7PcoRKMIjKmWjtJSI1t5GOQzHu/MatthieuRiccardHappinessAGuide toDevelopingLifesMostImportantSkill.pdf 
Rogers, C. R. (2012). On becoming a person: A therapist's view of psychotherapy. Houghton Mifflin Harcourt.

Ryan, R., \& Deci, E. (2001). On happiness and human potentials: A review of research on hedonic and eudaimonic well being. Annual Review of Psychology, 11-16. doi:0066-4308/01/0201-0141\$14.00

Sayegh, L., Anthony, W., \& Perrewe, P. (2004). Managerial decision-making under crisis: The role of emotion in an intuitive decision process. Human Resource Management Review, 14, 179-199. doi:10.1016/j.hrmr.2004.05.002

Seligman, M., \& Csikszentmihalyi, M. (2000). Positive psychology: An introduction. American Psychologist, 55, 5-14. doi:10.1037/0003066X.55.1.5

Seligman, M., Steen, T., Park, N., \& Peterson, C. (2005). Positive psychology progress. Empirical validation of interventions. American Psychologist, 60, 410-421. doi:10.1037/0003-066X.60.5.410

Sinclair, M., \& Ashkanasy, N. (2005). Intuition: Myth or a Decision-making Tool? Management Learning , 36, 353-370. doi:10.1177/1350507605055351 Sladek, R., Bond, M., \& Phillips, P. (2010). Age and gender differences in preferences for rational and experiential thinking. Personality and Individual Differences, 49, 907-911. doi:10.1016/j.paid.2010.07.028

Stark, R., \& Maier, J. (2008). Faith and happiness. Review of Religious Research, 50, 120-125. Retrieved from http://www.jstor.org/stable/20447531 Tabachnick, B., \& Fidell, L. (2014). Using Multivariate Statistics. Harlow, Essex: Pearson Education Limited.

Tat, H., Hooi, P., Rasli, A., Chin, T., \& Yusoff, R. (2010). The role of intuition in decision making: An empirical study on academic staff in a Malaysian public university. Retrieved from https://www.researchgate.net/publication/228534059

Walsh, W. B., Craik, K., \& Price, R. H. (2000). Person-environment psychology. Mahwah, NJ: Lawrence Erlbaum.

Watson, D., \& Tharp, R. (2013). Self directed behavior: Self modification for personal adjustment. Cengage Learning.

Witterman, C., van den Berken, J., Claes, L., \& Godoy, A. (2009). Assessing rational and intuitive thinking styles. European Journal of Psychological Assessment, 25, 39-47. doi:10.1027/1015-5759.25.1.39

Zhong, C. (2008). The ethical dangers of rational decision making. Academy of Management Proceedings, 1-6. Retrieved from http://connection.ebscohost.com/c/articles/33716790/ethical-dangersrational-decision-making 